\title{
Cisplatin in combination with programmed cell death protein 5 increases antitumor activity in prostate cancer cells by promoting apoptosis
}

\author{
WENBIN ZHU ${ }^{1}$, YANG $\mathrm{LI}^{1}$ and $\mathrm{LEI} \mathrm{GAO}{ }^{2}$ \\ Departments of ${ }^{1}$ Urology and ${ }^{2}$ Crushed Stones Center, Linyi People's Hospital, Linyi, Shandong 276003, P.R. China
}

Received December 30, 2013; Accepted October 3, 2014

DOI: $10.3892 / \mathrm{mmr} .2015 .3252$

\begin{abstract}
Prostate cancer is the most common type of cancer affecting males. The aim of the present study was to investigate the antitumor effect of cisplatin in combination with programmed cell death protein 5 (Pdcd5) on Du145 prostate cancer cells and to elucidate the underlying mechanisms of action. An MTT cell viability assay was performed in order to determine the proliferation rate of Du145 cells. The results demonstrated that Du145 cells treated with cisplatin for $48 \mathrm{~h}$ had an $\mathrm{IC}_{50}$ value $>200 \mu \mathrm{M}$; however, following transfection of Pdcd5 in combination with treatment with various concentrations of cisplatin, the proliferation rates of Du145 and PC3 prostate cancer cells were significantly decreased in a dose-dependent manner, with $\mathrm{IC}_{50}$ values of 114.1 and $50.6 \mu \mathrm{M}$, respectively. Annexin V-fluorescein isothiocyanate/propidium iodide dual labeling analyses demonstrated a significant increase in the apoptotic rate of Du145 cells following transfection of Pcdc5 in combination with cisplatin treatment. Furthermore, western blot analysis revealed a marked increase in activated caspase-3 expression in Du145 cells as well as a decreased ratio of $\mathrm{Bcl}-2 / \mathrm{Bax}$. In conclusion, the results of the present study demonstrated that Pdcd5 increased the chemosensitivity of prostate cancer cells and decreased the toxicity of cisplatin via activation of the receptor-associated apoptotic pathway; this may therefore indicate the combined use of cisplatin and Pdcd5 as a novel therapeutic strategy for the treatment of prostate cancer.
\end{abstract}

\section{Introduction}

Prostate cancer, a type of cancer affecting the male reproductive system, is the second most prevalent type of cancer worldwide (1), accounting for $10 \%$ of all cancers in males (2).

Correspondence to: Dr Lei Gao, Department of Crushed Stones Center, Linyi People's Hospital, 27 East Jiefang Road, Linyi, Shandong 276003, P.R. China

E-mail: leiagao@163.com

Key words: prostate cancer, programmed cell death 5, cisplatin, apoptosis
Recent studies have reported that prostate cancer has the third highest five-year survival rate of all cancers $(3,4)$; in addition, with the development of an aging population and improved quality of life, the incidence of prostate cancer has significantly increased in China $(5,6))$.

Chemotherapy is one of the primary treatment methods used in prostate cancer patients (7-9). Cisplatin (chemical structure shown in Fig. 1A), a chemotherapy drug also known as cisplatinum or cis-diamminedichloridoplatinum (II), is a member of the platinum-containing anticancer drug group, which also includes carboplatin and oxaliplatin $(10,11)$. Platinum complexes bind to and cause cross-linking of DNA in cancer cells, which in turn induces and triggers apoptosis. However, numerous chemotherapy drugs have adverse toxic effects, even at therapeutic doses. Therefore, it is necessary to investigate alternative therapeutic methods that may overcome drug toxicity in order to effectively treat prostate cancer (12).

Apoptosis was reported to be associated with the pathogenesis and progression of cancer. Programmed cell death protein (Pcdc) 5, an apoptosis-associated gene that was reported to have a key role in the pathogenesis and development of cancer, was first identified by Peking University Center for Human Disease Genomics (Beijing, China) in 1999 (13). Previous studies have demonstrated that decreased expression of Pdcd5 was observed in various types of human tumors, including breast cancer (14), cervical cancer (15), hepatocellular carcinoma (16), gastric cancer (17), lung cancer (18) and prostate cancer (19). In addition, transfection of Pdcd5 effectively repressed the growth of tumor cells, including ovarian, liver and cervical cancer cells, through the promotion of apoptosis $(15,20,21)$; however, one study reported that there was no significant difference between the serum levels of Pdcd5 in cancer patients and those of healthy controls (22).

Previous studies have demonstrated that Pdcd4 expression promoted chemosensitivity in the prostate and renal cancer cell lines PC3 and UO-31, respectively $(23,24)$; however, the effect of Pdcd5 expression on chemosensitivity and the required dose of chemotherapy drugs remains to be elucidated. The aim of the present study was to investigate the antitumor effect of cisplatin in combination with Pdcd5 on prostate cancer cells and to elucidate its underlying mechanism of action in order to produce a novel therapeutic strategy for the treatment of prostate cancer. 


\section{Materials and methods}

Cell culture and transfection. Du145 (ATCC ${ }^{\circledR}$ HTB-81 ${ }^{\mathrm{TM}}$ ) and PC3 (ATCC ${ }^{\circledR}$ CRL-1435 ${ }^{\mathrm{TM}}$ ) human prostate cancer cell lines (American Type Culture Collection, Manassas, VA, USA), which were preserved in liquid nitrogen until use, were cultured in Dulbecco's modified Eagle's medium (DMEM; Gibco, Grand Island, NY, USA) supplemented with $10 \%$ fetal calf serum (Gibco). The cells were plated in 24-well plates for $8 \mathrm{~h}$ prior to transfection or drug treatment. The pcDNA3.1 control (mock) plasmid and pcDNA3.1-Pdcd5 were constructed and then transfected into prostate cancer cells for $24 \mathrm{~h}$ using Lipofectamine 2000, according to the manufacturer's instructions (Invitrogen Life Technologies, Carlsbad, CA, USA). In brief, Lipofectamine 2000 and the Pdcd5 plasmid were each added to separate opti-MEM solutions (Gibco; $100 \mu \mathrm{l}$ ) and incubated for $5 \mathrm{~min}$. The two solutions were then combined and incubated at room temperature for a further $15 \mathrm{~min}$ prior to addition to the plated cells for transfection for $6 \mathrm{~h}$ at $37^{\circ} \mathrm{C}$, and $5 \% \mathrm{CO}_{2}$. The medium was then replaced with fresh DMEM plus $10 \%$ FBS and penicillin-streptomycin.

MTT assay. Cell viability and proliferation were determined using an MTT assay (Sigma, St. Louis, MO, USA), as previously described $(25,26)$. In brief, following transfection of Pdcd5 or the mock plasmid, $5 \times 10^{5}$ prostate cancer cells were seeded into 96-well plates and incubated with various concentrations of cisplatin $(0,10,50$ and $250 \mu \mathrm{M}$; Sigma) for 24,48 and $72 \mathrm{~h}$. Following incubation, $10 \mu \mathrm{l}$ of $5 \mathrm{mg} / \mathrm{ml}$ MTT reagent was added to the medium and cells were incubated for a further $4 \mathrm{~h}$. The medium was then drained and cells were treated with $150 \mu \mathrm{l}$ dimethyl sulfoxide for $15 \mathrm{~min}$. The plates were then analyzed using a microplate reader (Thermo Scientific, Waltham, MA, USA) at a test wavelength of $490 \mathrm{~nm}$.

Flow cytometric analysis. Following transfection, cisplatin-treated Du145 cells were subjected to Annexin V-fluorescein isothiocyanate (FITC)/propidium iodide (PI) dual labeling followed by fluorescence-activated cell sorting (FACS) analysis (Santa Cruz Biotechnology, Inc., Dallas, TX, USA), performed according to the manufacturer's instruction, in order to determine apoptosis. Each example recorded $>10,000$ events.

SDS-PAGE and western blot analysis. Whole cell extracts were prepared and separated using SDS-PAGE as previously described (27-29). Protein (30-60 $\mu \mathrm{g})$ was then transferred onto polyvinylidene fluoride (PVDF) membranes (Millipore, Billerica, MA, USA) and blocked using 1\% bovine serum albumin in Tris-buffered saline with $0.1 \%$ Tween-20 for $1 \mathrm{~h}$. The filters were then incubated overnight at $4^{\circ} \mathrm{C}$ with the following primary antibodies: Rabbit polyclonal Bax immunoglobulin (Ig)G $(1: 1,000)$, mouse monoclonal Bcl-2 IgG1 (1:1,000), rabbit polyclonal caspase-3 IgG (1:2,000), rabbit polyclonal cleaved caspase- 3 IgG $(1: 2,000)$ and mouse monoclonal $\beta$-actin IgG1 (1:2,000), which were all purchased from Santa Cruz Biotechnology, Inc. $\beta$-actin was used as an internal control. PVDF membranes were then washed three times with phosphate-buffered saline with $0.1 \%$ Tween 20 and then incubated with goat anti-mouse secondary antibodies (Santa Cruz
A<smiles>N[Pb](N)(Cl)Cl</smiles>

B
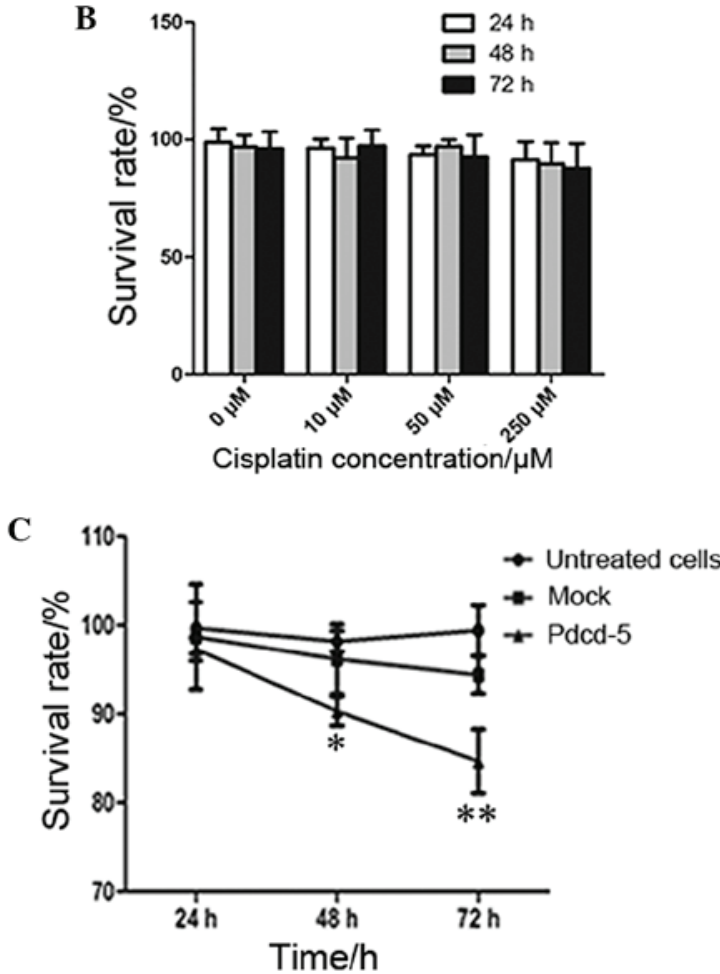

Figure 1. MTT assays determine the survival rates of Du145 prostate cancer cells following cisplatin treatment and Pdcd5 transfection. (A) Chemical structure of cisplatin. (B) Survival rate of Du145 cells following treatment with various concentrations of cisplatin $(0,10,50$ and $250 \mu \mathrm{M})$ for 24,48 and 72 h. (C) Cell viability of Du145 cells transfected with the Pdcd5 or mock plasmid vectors following cisplatin treatment for 24,48 and $72 \mathrm{~h}$. Values are presented as the mean \pm standard deviation $(n=3)$. ${ }^{*} \mathrm{P}<0.05$ vs. untreated cells, ${ }^{* * *} \mathrm{P}<0.01$ vs. untreated cells. Pdcd5, programmed cell death protein 5; mock, cells transfected with an empty vector.

Biotechnology, Inc.) conjugated with peroxidase for $1 \mathrm{~h}$ at room temperature. Membranes were then washed and signals were visualized using SuperSignal West Pico Chemiluminescent Substrate (Pierce Biotechnology, Inc., Rockford, IL, USA). Image-Pro Plus software (Media Cybernetics, Inc., Rockville, MD, USA) was used for analysis.

Statistical analysis. All experiments were performed a minimum of three times. Data were analyzed using SPSS 11.5 software (SPSS, Inc., Chicago, IL, USA). Values are presented as the mean \pm standard deviation. $\mathrm{P}<0.01$ was considered to indicate a statistically significant difference.

\section{Results}

Combined antitumor activity of cisplatin and Pdcd5 in Dul45 cells. Previous studies have demonstrated that Du145 cells were highly resistant to cisplatin treatment 30,31). In the present study, an MTT assay was used to determine the viability of Du145 cells in order to evaluate the anti- 
A

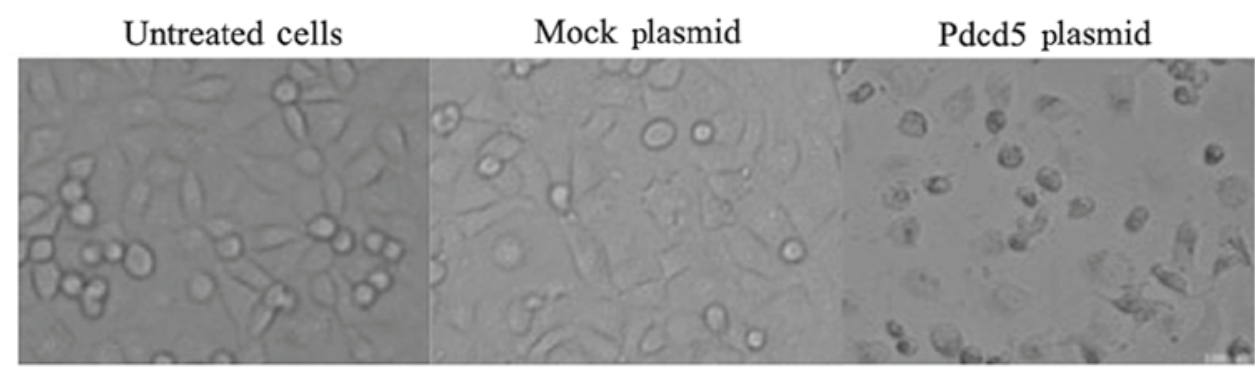

B

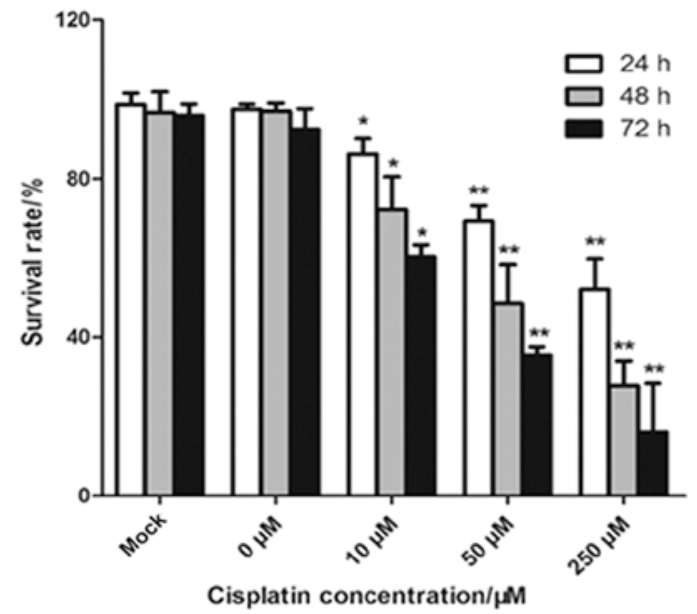

Figure 2. Effect of Pdcd5 overexpression on the chemosensitivity of Du145 prostate cancer cells. (A) Morphological changes of Du145 following transient transfection of a Pdcd5 or mock vector (magnification, x200). (B) An MTT assay was used to detect cell viability of mock- and Pdcd5-transfected Du145 cells treated with various concentrations of cisplatin $(0,10,50$ and $250 \mu \mathrm{M})$ for 24,48 and $72 \mathrm{~h}$. Values are presented as the mean \pm standard deviation (n=3). ${ }^{*} \mathrm{P}<0.05$ vs. mock vector, ${ }^{* *} \mathrm{P}<0.01$ vs. mock vector. $\mathrm{Pdcd} 5$, programmed cell death protein 5.

A

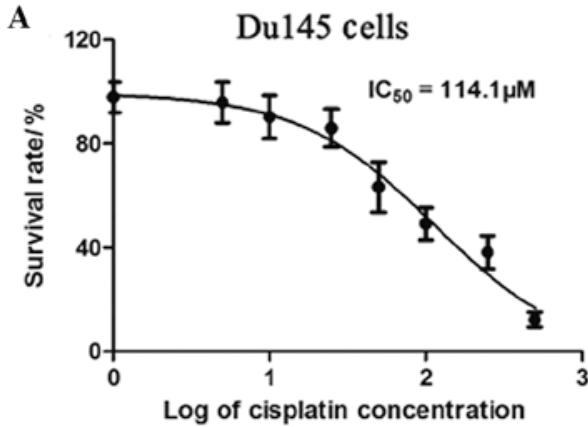

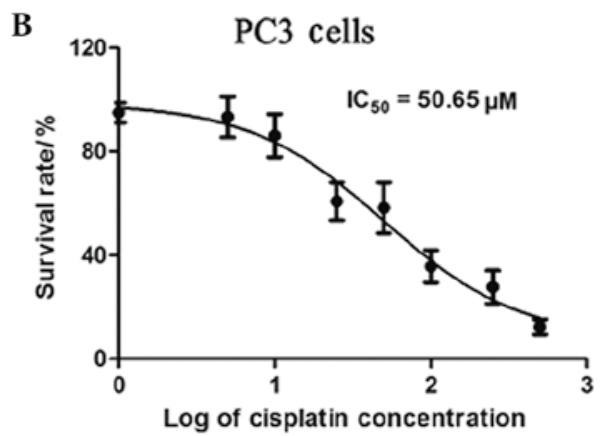

Figure 3. Cell viability of Du145 and PC3 prostate cancer cells following transfection of Pdcd5. MTT assays were used to determine the IC ${ }_{50}$ values of (A) Du145 and (B) PC3 cells following treatment with various concentrations of cisplatin $(1,5,10,25,50,100,250$ and $500 \mu \mathrm{M})$ for $48 \mathrm{~h}$. Values are presented as the mean \pm standard deviation $(n=3)$. Pdcd5, programmed cell death protein 5 .

tumor activity of cisplatin. As shown in Fig. 1, different concentrations of cisplatin were used to treat Du145 cells for 24, 48 and $72 \mathrm{~h}$. The results demonstrated that there was no significant decrease in cell viability at any concentration of cisplatin (Fig. 1B); however, at 48 and $72 \mathrm{~h}$ post-transfection of Pdcd5, the survival rate of Du145 cells was significantly inhibited compared with that of the untreated cells.

Overexpression of Pdcd5 increases chemosensitivity of Dul45 prostate cancer cells to cisplatin. In order to further examine the effects of cisplatin on cellular proliferation in the presence of Pdcd5, Du145 cells were transfected for $48 \mathrm{~h}$ with pcDNA3.1-Pdcd5 in order to overexpress Pdcd5 and then incubated with various concentrations of cisplatin for 24,48 and $72 \mathrm{~h}$. An MTT assay was the used to determine cell viability of the prostate cancer cells. As shown in Fig. 2A, Pdcd5-transfected cells treated with $50 \mu \mathrm{M}$ cisplatin revealed marked cell death compared with those of the untreated and mock vector-transfected cells. In addition, the rates of cell survival demonstrated time- and dose-dependent decreases compared with those of the untreated mock vector- and Pdcd5-transfected cells (Fig.2B). This therefore indicated that Du145 cells transfected with Pdcd5 had an increased sensitivity to cisplatin.

As shown in Fig. 3, an MTT assay was also used to determine the $\mathrm{IC}_{50}$ values in the Du145 and PC3 prostate cancer cell lines. Following transfection of Pdcd5, Du145 and PC3 

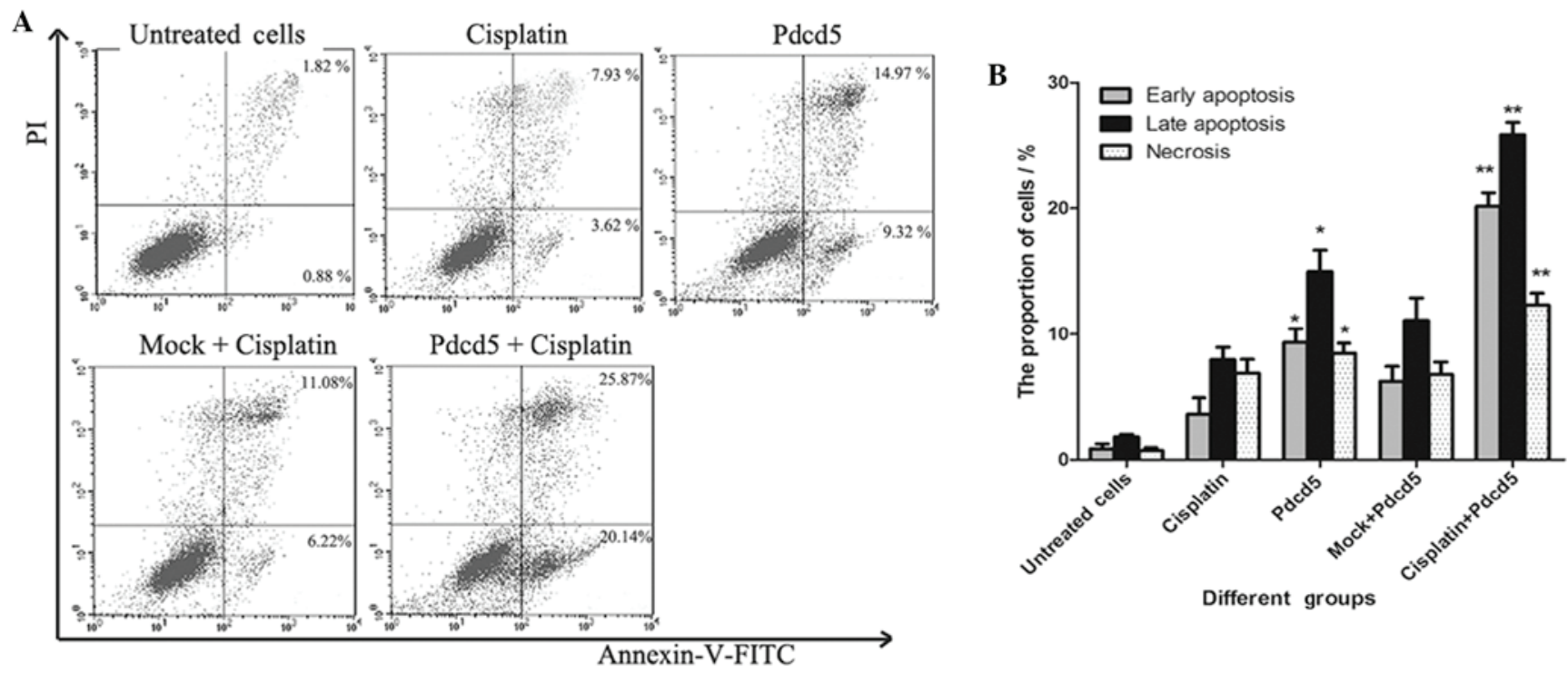

Figure 4. Annexin V-FITC/PI staining and fluorescence-activated cell sorting analysis of apotosis in Du145 cells following transfection of Pdcd5 and cisplatin treatment. (A) Analysis of apoptosis in Du145 cells transfected with Pdcd5 or mock plasmind vectors with or without cisplatin treatment for $24 \mathrm{~h}$. (B) Histogram of apoptotic rates of Du145 cells in different treatment groups. Values are presented as the mean \pm standard deviation ( $\mathrm{n}=3$ ). Pdcd5, programmed cell death protein 5; FITC, fluorescein isothiocyanate; PI, propidium iodide.

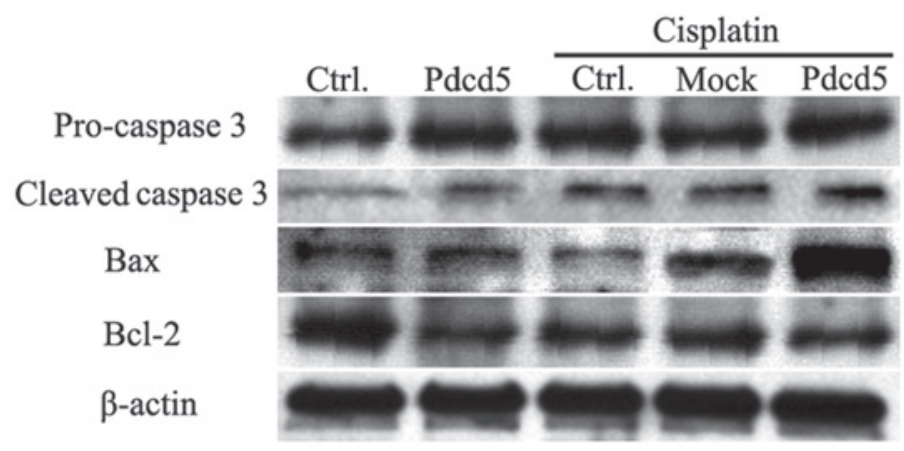

Figure 5. Western blot analysis of apoptosis-associated protein expression levels in Pdcd5-transfected Du145 prostate cancer cells following treatment with $50 \mu \mathrm{M}$ cisplatin. Du145 cells were treated with $50 \mu \mathrm{M}$ cisplatin for $24 \mathrm{~h}$. $\beta$-actin was used as an internal control. Ctrl, control group of untransfected Du145 cells.

cells were exposed to various concentrations of cisplatin for $48 \mathrm{~h}$. The $\mathrm{IC}_{50}$ values were 114.1 and $50.6 \mu \mathrm{M}$ in Du145 and PC3 cells, respectively, indicating the synergistic effects of transfection of Pdcd5 and cisplatin treatment.

Pdcd5 promotes cisplatin-induced apoptosis. FACS analysis using Annexin V-FITC and PI staining was performed in order to determine whether the cisplatin-induced decrease in cell survival was due to apoptosis. As shown in Fig. 4, the apoptotic rate of Du145 cells transfected with Pdcd5 was significantly increased compared with that of the control group following cisplatin treatment for $24 \mathrm{~h}$. In addition, the apoptotic rate of untreated Pdcd5-overexpressing cells was significantly increased compared with that of the untreated control cells. These results were consistent with those determined by MTT assays.

Pdcd5 promotes apoptosis-associated protein expression following treatment with cisplatin. Western blot analysis was performed in order the detect the expression levels of several apoptosis-associated proteins. As shown in Fig. 5, following treatment with cisplatin for $24 \mathrm{~h}$, the expression levels of cleaved caspase- 3 in Pdcd5 transfected cells was markedly increased compared with those of cells transfected with the mock plasmid. In addition, there was no significant difference in Bcl-2 expression in Pdcd5-transfected Du145 cells following cisplatin treatment; however, the protein expression levels of Bax were significantly increased. Therefore, following cisplatin treatment, the $\mathrm{Bcl}-2 / \mathrm{Bax}$ ratio was significantly decreased in Pdcd5-transfected Du145 cells. In conclusion, Pdcd5-transfected Du145 cells demonstrated a significantly increased level of chemosensitivity to cisplatin and a time- and dose-dependent increase in the rate of apoptosis following cisplatin treatment.

\section{Discussion}

Prostate cancer is one of the most prevalent types of cancer worldwide, which is diagnosed in $\sim 80 \%$ of male cancer patients who reach 80 -years-old (32). Cisplatin has a broad spectrum 
of antitumor activities and increases the antitumor sensitivity of chemotherapy drugs (33-35). Cisplatin is commonly used as a chemotherapy drug for the treatment of solid tumors and blood cancer (36); previous studies have confirmed that cisplatin promotes apoptosis in numerous types of tumor cells $(37,38)$. However, the therapeutic application of cisplatin is limited by tumor drug resistance and systemic toxicity. At high doses, cisplatin toxicity increases $(39,40)$; whereas low doses of cisplatin are not effective for the treatment of prostate cancer. Therefore, a comprehensive therapy that improves the current status of cancer chemotherapy is required. It was suggested that gene therapy in combination with cisplatin may be a potential novel therapeutic method for the treatment of cisplatin-resistant tumors.

The aim of the present study was to investigate the effect of Pdcd5 transfection in combination with cisplatin treatment on Du145 prostate cancer cells. The results demonstrated that the proliferation rate of transfected Du145 cells following cistplatin treatment was significantly inhibited compared with that of the untreated and mock transfection groups; $\mathrm{IC}_{50}$ values decreased from $>200$ to $114.1 \mu \mathrm{M}$ following transfection.

Pdcd5 was first identified by Peking University Center for Human Disease Genomics (Bejing, China), where it was found to regulate apoptosis in numerous cell types (13).Pdcd5 is expressed in various tissues, with low levels of expression in numerous types of cancer, including liver, lung and colon cancers (15,41-43). It was previously reported that Pdcd5 also had important roles in the development and progression of cancer (22). In the present study, an expression vector was constructed in order to overexpress the Pdcd5 gene in prostate cancer cells. The results of an MTT assay and Annexin V-FITC/PI staining demonstrated that the overexpression of Pdcd5 significantly induced apoptosis in Du145 cells; in addition, western blot analysis revealed that Pdcd5 transfection in combination with cisplatin treatment significantly increased the protein expression levels of apoptosis-associated factors, including cleaved caspase- 3 and Bax in Du145 cells, as well as decreased the ratio of $\mathrm{Bcl}-2 / \mathrm{Bax}$ proteins. This therefore indicated that Pdcd5 promoted the chemosensitivity of prostate cancer cells to cisplatin, as well as decreased cisplatin toxicity via activation of apoptotic pathways. However, further studies are required in order to determine whether apoptosis was induced via receptor-mediated or mitochondria-associated apoptotic pathways.

In conclusion, gene therapy in combination with cisplatin treatment demonstrated promising results as a potential novel treatment for prostate cancer. The results of the present study demonstrated that overexpression of Pdcd5 induced a significant increase in apoptosis and decreased cell proliferation in Du145 cells through enhancing the chemosensitivity of cells to cisplatin; as demonstrated by the decrease in $\mathrm{IC}_{50}$ values of cisplatin on Du145 cells following transfection with Pdcd5. This therefore indicated that following gene therapy, lower doses of chemotherapy drugs may be required for the effective treatment of prostate cancer, which in turn may reduce the toxicity of anticancer drugs in patients.

\section{References}

1. Wallner LP and Jacobsen SJ: Prostate-specific antigen and prostate cancer mortality: a systematic review. Am J Prev Med 45: 318-326, 2013.
2. Thomsen FB, Brasso K, Klotz LH, Røder MA, Berg KD and Iversen P: Active surveillance for clinically localized prostate cancer - a systematic review. J Surg Oncol 109: 830-835, 2014.

3. van den Bergh RC, Albertsen PC, Bangma CH, et al: Timing of curative treatment for prostate cancer: a systematic review. Eur Urol 64: 204-215, 2013.

4. Punnen S, Cooperberg MR, D'Amico AV, et al: Management of biochemical recurrence after primary treatment of prostate cancer: a systematic review of the literature. Eur Urol 64: 905-915, 2013.

5. Wang Y, Sun G, Pan JG, Guo ZJ and Li T: Performance of tPSA and $\mathrm{f} / \mathrm{tPSA}$ for prostate cancer in Chinese. A systematic review and meta-analysis. Prostate Cancer Prostatic Dis 9: 374-378, 2006.

6. Wilkinson S and Chodak GW: Critical review of complementary therapies for prostate cancer. J Clin Oncol 21: 2199-2210, 2003.

7. Parekh A, Graham PL and Nguyen PL: Cancer control and complications of salvage local therapy after failure of radiotherapy for prostate cancer: a systematic review. Semin Radiat Oncol 23: 222-234, 2013.

8. Murray L, Henry A, Hoskin P, Siebert FA and Venselaar J; BRAPHYQS/PROBATE group of the GEC ESTRO: Second primary cancers after radiation for prostate cancer: a review of data from planning studies. Radiat Oncol 8: 172, 2013.

9. Matos CS, de Carvalho AL, Lopes RP and Marques MP: New strategies against prostate cancer - Pt(II)-based chemotherapy. Curr Med Chem 19: 4678-4687, 2012.

10. Dhar S, Kolishetti N, Lippard SJ and Farokhzad OC: Targeted delivery of a cisplatin prodrug for safer and more effective prostate cancer therapy in vivo. Proc Natl Acad Sci USA 108: 1850-1855, 2011.

11. Menen R, Zhao M, Zhang L, et al: Comparative chemosensitivity of circulating human prostate cancer cells and primary cancer cells. Anticancer Res 32: 2881-2884, 2012.

12. Seifert M and Reichrath J: The role of the human DNA mismatch repair gene hMSH2 in DNA repair, cell cycle control and apoptosis: implications for pathogenesis, progression and therapy of cancer. J Mol Histol 37: 301-307, 2006.

13. Liu H, Wang Y, Zhang Y, et al: TFAR19, a novel apoptosis-related gene cloned from human leukemia cell line TF-1, could enhance apoptosis of some tumor cells induced by growth factor withdrawal. Biochem Biophys Res Commun 254: 203-210, 1999.

14. Hedenfalk I, Duggan D, Chen Y, et al: Gene-expression profiles in hereditary breast cancer. N Engl J Med 344: 539-548, 2001.

15. Liu ZH, Zhang D, Li KM and Liao QP: Expression of Pdcd5 in tissues of normal cervix, CIN I-III and cervical cancer. Beijing Da Xue Xue Bao 36: 407-410, 2004 (In Chinese).

16. Xu XR, Huang J, Xu ZG, et al: Insight into hepatocellular carcinogenesis at transcriptome level by comparing gene expression profiles of hepatocellular carcinoma with those of corresponding noncancerous liver. Proc Natl Acad Sci USA 98: 15089-15094, 2001.

17. Yang YH,Zhao M,Li WM, et al: Expression of programmed cell death 5 gene involves in regulation of apoptosis in gastric tumor cells. Apoptosis 11: 993-1001, 2006.

18. Spinola M, Meyer P, Kammerer S, et al: Association of the Pdcd5 locus with lung cancer risk and prognosis in smokers. J Clin Oncol 24: 1672-1678, 2006.

19. Du YJ, Xiong L, Lou Y, Tan WL and Zheng SB: Reduced expression of programmed cell death 5 protein in tissue of human prostate cancer. Chin Med Sci J 24: 241-245, 2009.

20. Zhang X, Wang X, Song X, et al: Clinical and prognostic significance of lost or decreased PDCD5 expression in human epithelial ovarian carcinomas. Oncol Rep 25: 353-358, 2011.

21. Chen Y,Zou Z, Xu A, Liu Y, Pan H and Jin L: Serum programmed cell death protein 5 (PDCD5) levels is upregulated in liver diseases. J Immunoassay Immunochem 34: 294-304, 2013.

22. Wang Y, Wang GH and Zhang QY: Determination of Pdcd5 in peripheral blood serum of cancer patients. Chin J Cancer Res 23: 224-228, 2011.

23. Shiota M, Izumi H, Tanimoto A, et al: Programmed cell death protein 4 down-regulates Y-box binding protein-1 expression via a direct interaction with Twist1 to suppress cancer cell growth. Cancer Res 69: 3148-3156, 2009.

24. Jansen AP, Camalier CE, Stark C and Colburn NH: Characterization of programmed cell death 4 in multiple human cancers reveals a novel enhancer of drug sensitivity. Mol Cancer Ther 3: 103-110, 2004.

25. Bernas T and Dobrucki J: Mitochondrial and nonmitochondrial reduction of MTT: interaction of MTT with TMRE, JC-1, and NAO mitochondrial fluorescent probes. Cytometry 47: 236-242, 2002 . 
26. Sylvester PW: Optimization of the tetrazolium dye (MTT) colorimetric assay for cellular growth and viability. Methods Mol Biol 716: 157-168, 2011.

27. Nishitani H, Sugimoto N, Roukos V, et al: Two E3 ubiquitin ligases, SCF-Skp2 and DDB1-Cul4, target human Cdt1 for proteolysis. EMBO J 25: 1126-1136, 2006.

28. Peng L, Xu Z, Zhou Y, et al: Effect of rosiglitazone on cells cycle, apoptosis and expression of Skp2 and p27Kip1 in hepatocellular carcinoma cell line. Zhonghua Gan Zang Bing Za Zhi 18: 148-149, 2010 (In Chinese).

29. Schulman BA, Carrano AC, Jeffrey PD, et al: Insights into SCF ubiquitin ligases from the structure of the Skp1-Skp2 complex. Nature 408: 381-386, 2000.

30. Amantana A, London CA, Iversen PL and Devi GR: X-linked inhibitor of apoptosis protein inhibition induces apoptosis and enhances chemotherapy sensitivity in human prostate cancer cells. Mol Cancer Ther 3: 699-707, 2004.

31. Li Y, Chen HQ, Chen MF, et al: Neuroendocrine differentiation is involved in chemoresistance induced by EGF in prostate cancer cells. Life Sci 84: 882-887, 2009.

32. Larkin D, Lopez V and Aromataris E: Managing cancer-related fatigue in men with prostate cancer: A systematic review of non-pharmacological interventions. Int J Nurs Pract Nov 15 2013 (Epub ahead of print).

33. Kao CJ, Wurz GT, Monjazeb AM, et al: Antitumor effects of cisplatin combined with tecemotide immunotherapy in a human MUC1 transgenic lung cancer mouse model. Cancer Immunol Res 2: 581-589, 2014.

34. de Biasi AR, Villena-Vargas $\mathrm{J}$ and Adusumilli PS Cisplatin-Induced Antitumor Immunomodulation: A Review of Preclinical and Clinical Evidence. Clin Cancer Res 20: 5384-5391, 2014
35. Sun S, Tang L, Zhang J, et al: Cisplatin improves antitumor activity of weekly nab-paclitaxel in patients with metastatic breast cancer. Int J Nanomedicine 9: 1443-1452, 2014

36. Itoh $\mathrm{T}$, Terazawa $\mathrm{R}$, Kojima $\mathrm{K}$, et al: Cisplatin induces production of reactive oxygen species via NADPH oxidase activation in human prostate cancer cells. Free Radic Res 45: 1033-1039, 2011.

37. Murshed F, Farhana L, Dawson MI and Fontana JA: NF- $\kappa B$ p65 recruited SHP regulates Pdcd5-mediated apoptosis in cancer cells. Apoptosis 19: 506-517, 2014.

38. Xu HY, Chen ZW, Pan YM, et al: Transfection of Pdcd5 effect on the biological behavior of tumor cells and sensitized gastric cancer cells to cisplatin-induced apoptosis. Dig Dis Sci 57: $1847-1856,2012$

39. Kaeidi A, Rasoulian B, Hajializadeh Z, Pourkhodadad S and Rezaei M: Cisplatin toxicity reduced in human cultured renal tubular cells by oxygen pretreatment. Ren Fail 35: 1382-1386, 2013.

40. Motawi TK, Abd-Elgawad HM and Shahin NN: Effect of protein malnutrition on the metabolism and toxicity of cisplatin, 5 -fluorouracil and mitomycin $\mathrm{C}$ in rat stomach. Food Chem Toxicol 56: 467-482, 2013.

41. Wang L, Wang C, Su B, et al: Recombinant human Pdcd5 protein enhances chemosensitivity of breast cancer in vitro and in vivo. Biochem Cell Biol 91: 526-531, 2013.

42. Li SJ, Yu J, Zhao XF, et al: Pdcd5 induces the apoptosis of human prostate cancer cells PC-3M-1E8. Zhonghua Nan Ke Xue 13: 979-982, 2007 (In Chinese).

43. Yin A, Jiang Y, Zhang X, Zhao J and Luo H: Transfection of Pdcd5 sensitizes colorectal cancer cells to cisplatin-induced apoptosis in vitro and in vivo. Eur J Pharmacol 649: 120-126, 2010. 